\title{
Re-storing the Earth: A Phenomenological Study of Living Sustainably
}

\author{
Jessica Belue Buckley, University of Maryland, College Park, Maryland
} Email: jbuckley@umd.edu

\section{Abstract}

Living sustainably evokes ideas of lived, bodily engagement with and perception of the earth. Yet, modern ways of thinking and speaking have slowly alienated the earth from consciousness. Using phenomenological methods, the author examines the experience of living sustainably, exploring her own background and the idea of restoring the earth to consciousness, before examining the lives of two students dedicated to living sustainably. Components of upholding the earth, in-volving humanity, perceiving differences in studying and embodying sustainability, and engaging in choices fill the experience of living sustainably.

\section{Introduction}

Moran (2000) highlights Merleau-Ponty's thought: "We can never grasp the world in its totality but we grasp it according to the mode in which we inhabit it" (p. 430). Merleau-Ponty elicits both the esoteric nature of understanding the world in its entirety while exposing the inherent existence of humanity in the world. We exist in that which we cannot fully define. Yet, humanity does frequently define the world. Through contemporary notions of sustainability, humanity also seeks to define what is good for the world - for the earth, economies, and communities. Contemporary media and culture, however, have used the term "sustainability" such that it has become overused with little authentic meaning. Signs, labels, and messages implore consumers to be, buy, and live sustainably without considering the essence of the term.

Knowing the many forces - rooted in history, language, philosophy, and simple convenience - that hinder a person from living sustainably, what does it mean to live sustainably? Berry (2002a) suggests, "We haven't yet, in any meaningful sense, arrived in the places that we declare we own" (p. 27). To live sustainably, we must "apply our minds directly and competently to the needs of the earth" and in doing so will "make fundamental and necessary changes in our minds" (2002b, p. 89). He argues while we inhabit and use the land, we rarely truly consider, observe, or acknowledge the land. Assuming, as I explore in this paper, sustainability entails perceptively arriving in the places around us and living with the earth in mind, in what ways does living sustainably bring one into awareness of the earth? Does one experience a lived knowledge of the issues of climate change, global development, and the disproportional affects of climate change on the world's poor? Such abstract concepts must not be easy to experience in a lived way. 
Yet, we do experience components of what we envision as climate change, pollution, and earthly responses to human inhabitation over time as we infuse rational, cognitive education with a perceptive education. We experience the smell of the forest after a rain. We feel the earth beneath our feet as we walk across the ground. We hold our noses as we lift the lid to the trashcan. We experience, or perhaps just witness second-hand, the struggle of those whose homes are destroyed in ever more frequent floods. As a child, I felt the power of the earth as I sat with my parents watching the thunderstorm consume our small world. I witnessed the sense of duty my sister upheld as she saved items that might be renewed rather than thrown into a landfill. The presence of these moments and the awareness of connections between earth and humanity each fill actual, physical, emotional experiences that engage but do not exhaust cognitive experience. Living sustainably seemingly requires a perception of the earth, of others, and of the connections between the two. Yet, it arguably also requires the perception that as we live, "we are causing the [environmental] crisis" (Berry, 2002b, p. 83). How then do those who live sustainably perceive?

The thought of perceiving the earth seems rooted in a sustainable mindset. "Merleau-Ponty spent much of his life demonstrating that the event of perception unfolds as a reciprocal exchange between the living body and the animate world that surrounds it" (Abram, 1996, p. 73). Thus, our perception of the world is embodied through our own physical presence in the world and is also our response to the world. Perception of the earth recognizes that the earth offers a kind of knowledge I can, in fact, experience and seek to understand. As I turn to the question, therefore, I seek to understand how humans perceive the earth and live in light of that perception.

Borrowing a phrase from David Orr (2004), I explore the experience of living with the "earth in mind." As we return earth to mind, we re-store earth to our awareness in a culture that has largely failed to "arrive" (Berry, 2002a, p. 27) consciously into awareness of earth. While humanity has largely moved in such a way as to "resist" the landscape (Berry, p. 12), some work against a contemporary almost default blindness toward the earth to re-store earth to consciousness. Living with earth in mind invites a way of living not possible when we fail to perceive its existence around us. Using a phenomenological lens, I first turn to my own experiences and education, examining the ideas of sustainability and earth. Then, I turn to the lives of two women devoted to sustainability on a college campus. The lived experiences of these women who live, study, and work with the earth in mind give insight into what it means to live sustainably.

\section{Awakening into a Lifestyle: Living with Earth in Mind}

Myriad memories awaken me to my ongoing path of understanding of sustainability. A term that is at once shrouded in heavily-researched scientific concepts and also indicative of a possible poetic sensibility towards the earth, sustainability can take on different meanings to each one who lives with the earth and humanity in mind. What then is sustainability and what meanings does it carry in a life? Why have I come to be curious about this word and lifestyle? If I were to follow my own sustainable sensibilities back to their origin, I might first travel to a quiet Sunday afternoon in the woods behind my grandmother's house.

The crunch of the leaves under my feet pushes me forward as I make a bigger than necessary step up the hollow (hear: "holler"). "Crunch, crackle, crunch" becomes the 
soundtrack as I walk up the hill behind Mema's house. Dad is following close behind, picking up a bit of tattered paper here, an old soda can there. We are out exploring the woods behind my grandmother's house, and Dad is showing me the places that fill his bedtime stories. Mean Leonard and his one-eyed dog live in these woods, and this hollow gives them food, respite, and shelter. As we near the top of the hill, Dad tells about their adventures finding a coyote family that has just moved in. As the years, continue, I learn the names of leaves (since forgotten) and watch as my sister brings home recycling from her college campus that has no recycling program in 1992. I live in a community where I learn to compost. In graduate school, I begin to learn about the connections of environmental degradation and social injustice, learning patterns of global consumption and natural resource use.

Through moments outside, I began to appreciate the earth, its power and beauty. As I grew, I began to understand that the earth was not simply a statuary place of beauty. It is a being with which I am in relationship, whether I engage that relationship or not. In turn, each person's relationship with the earth is affected by my own actions. What might it mean to live in relationship with the earth - an object, albeit a living one? The Online Etymology Dictionary (2010) shares that the term "relation" is traced through the Old French to the Latin word "relationem," meaning a "bringing back or restoring." To live in relation to the earth, therefore, is to bring the earth back into our minds and hearts. To re-store the earth, we must ensure the earth is something we consider as we carry out daily routines, not only on occasional retreats in nature. Yet, earth is easy to overlook in a contemporary culture.

In one example, the way I experience and treat trash conjures the ways I dismiss the earth from my mind when, in fact, the earth is tangibly present. Almost every day I say, "I'll throw this away." In English, at least in the United States, we colloquially throw trash "away." The Online Etymological Dictionary (2010) says that away is from the Old English, aweg, meaning "on from this (that) place." Thus, when we throw something away, we throw it "on from this place." We throw it anywhere but our current place - it moves from our sight and from our mind; when the trash is gone, we have not only removed it from our current place, we have also succeeded in fulfilling a social responsibility. Refraining from littering, throwing trash "away" is considered a civic duty. Not until recently have I begun to question if this civic duty might be a part of an overall culture of trash that encourages my unquestioned complacency in ignoring the earth. Instead of acknowledging the physical place on or in earth where trash remains, my imagination of the life of trash stops at the garbage can. I place it into the bin, and it is magically away.

In this culture of trash, in which I throw trash "away" I also take the trash "out." Awaywhich is invisible in a culture that defines this place by the very nature that is any other place that is not here, with me - becomes synonymous with "out." While away in our consciousness is nothingness, it is, in fact, a physical, literal place on the earth. My language helps hint at the earth as I take the trash "out" of my home, my place of rest, hearth, and inclusion, into the outside where the earth and nature seem to reside when noticed. When I make "away" invisible, I make the earth invisible. When I take my trash "out," I accept that trash belongs in a vague space outside my home, thereby neglecting the real, tangible existence of the earth that resides "out." When I neglect to hold earth in mind, I neglect to truly see the ways in which my rituals with trash dismiss the home trash ultimately finds in the earth. My current culture of trash does not encourage me to re-store the earth in mind and in relationship but to ignore the earth in dismissal.

The notion that I might say I have a "culture" of trash and then seek to describe it elucidates 
an ironic way of living in which I recognize and perpetuate rituals that maintain the very presence of items I have deemed not worthy of maintaining. These rituals have become normal, unquestioned. As a society, we dutifully collect and steward the placement of trash. We seek to rid it from visibility, yet it surrounds and permeates our lives. Most rooms in a house have a container for trash. Rubbish bins exist on street corners. Each week, we engage in rituals of visiting the trash chute, rolling a can to the street, or dividing items no longer wanted. A one year old says clearly "stinky, trash," learning early the precious yet harrowing canister that is inviting but not to be touched. Yet, we rarely spend the same amount of daily or weekly time considering or tending to the earth. Living sustainably calls us to awaken to the tangible reality of all that is around us - from the earth to our trash - and acknowledge the relationships benign and malignant we may foster or ignore.

While such statements about a culture of trash cannot be made without acceptance of the hypocrisy inherent in then using, participating in, and recognizing the current necessity of the rituals of trash, it is worthy of nothing that trash helps demonstrate that when we make our relationship with the earth invisible, we fail to see the consequences of our actions to their full end. We create cultures and meanings that allow our responsibility to end at our driveway or trash chute, rather than to continue into the landfill, across the river, and through our neighbor's community. As Arendt described, a number of historical events have led us to experience "a loss of the world itself, [a] retreat from the earth, 'earth alienation"” (Moran, 2000, p. 309).

And, trash is a single example. As I have with trash, I might take a close examination at any number of daily experiences and un-earth the ways in which language and ritual work to sever my consciousness of my relationship with earth. Yet, the memories, experiences, and lessons I mentioned call me to look carefully and perceptively at the way I live in order to restore earth to mind by living sustainably.

The memories and feelings of childhood, the role models and lessons of adolescence, the readings and critical thought from young adulthood have in each turn nudged me to examine and change the ways I engage with the world. They awaken me to the earth, to the connections of the earth and humanity, and to my ability to make decisions that support those connections. I must learn to live differently - if imperfectly - with the mindfulness that the earth and others are recipients of the consequences of my actions. In awakening to the earth, I learn to recognize the earth despite a historical trajectory that has depleted a cultural consciousness of the earth. Yet, many times, alienating the earth is easy because denying it, ignoring it, or trampling it is an engrained cultural endeavor. The foods I eat, transportation I take, waste I produce, things I buy and consume, water I use all now involve a number of complex internal negotiations.

Showering: Just one more minute - it's so warm! But I shouldn't. I know the effects of heating water, using unnecessary water. But just one more minute can't hurt that much. It's a small luxury I can allow myself, right? But how does this affect communities around the world losing homes because of climate change?

Working: I would enjoy some tea, but I forgot my thermos. Maybe they have ceramic. They don't? I could recycle the paper cup, the sleeve, and the plastic top right? But I don't want to contribute more waste than I have to. Do I really need it? I have commitments until late this evening. Why did I forget my thermos?!

I negotiate with myself over how much my decisions may impact the earth, neighbors, or 
future generations. The earth has become part of a community of people in my mind because it is the very being that sustains each person. The earth ties us together by giving us shared ground, sustenance, and a place for community. Sustainability, therefore, has for me involved awakening to a lifestyle that seeks to perceive the earth in places where it is rendered out of mind. It involves thinking about connections among the earth, others, and myself. Some sustainable decisions become habit - to turn the light off before I leave the room. Some require a conscious effort in which I make decisions within a backdrop of convenience and comfort - I will turn the shower off, I will not purchase a beverage, I will begin to see my relationship with earth in each action. In each case, though, sustainability has become if not a lifestyle at least a conversation that flows through my each day and interaction.

\section{The Road to the Question: From Dismissing to Re-storing the Earth}

We have lived our lives by the assumption that what was good for us would be good for the world. We have been wrong. We must change our lives so that it will be possible to live by the contrary assumption, that what is good for the world will be good for us. And that requires that we make the effort to know the world and learn what is good for it. (Berry, 2004, p. 196)

As I turn attention to the awareness of the earth, a global community, and sustainability in my own life, I consider what living sustainably actually is. What is the experience of living sustainably? What elements are important to such an experience? How do we learn about sustainability, what does it mean to us, and how do we practice it?

The most often used definition of sustainability states that the term means "[meeting] the needs of the present without compromising the ability of future generations to meet their own needs" (World Commission on Environment and Development, 1987). Typically, sustainability is seen as the intersection of a healthy environment, a healthy economy, and a socially just society. Sustainability, from this definition, is a meeting and fulfilling of needs. Its definition starts with a gerund, a verb-turned noun. It is an action, a verb, cloaked as a thing, a noun. Rather than being an object that can be analyzed from a distance, therefore, sustainability is an action that requires actors who are wound up in that action closely because they perform the action. The kind of action sustainability requires is not any action, but one that entails thinking complexly and enacting long-term vision as people meet the needs of a growing and future population.

In one example, I might enact sustainability if when I eat, I do so in a way that does not limit future generations from acquiring food.

I walk through the store knowing our weekly budget. Organic milk -- it is more expensive but I would rather support those limiting chemicals in farming. What do the chemicals mean for long-term use of the soil? Look - local apples! But they are not organic. The organic apples are from ... I do not see any info. Oh, here -- from hundreds of miles away. Maybe I'll get a few of each? Which is worse long term -- the carbon emissions from food transport or effects of pesticide and fertilizer? I am supposed to take candy for a meeting, but all these fair trade chocolate bars are so expensive. Should I get a few of these or a big bag of something else? Four of the fair 
trade bars are $\$ 20$. What kind of quality of life did workers have who helped make the non fair trade chocolate? What am I supporting if I buy them? And if I don't?

Buying and eating food, however, are just two of perhaps a myriad of actions that could be done in a sustainable way. Potential actions face us at every corner as checklists abound for ways in which we might act sustainably - buy nothing, or if you must consume, buy local, fair trade, organic. As I write, I see on the desk in front of me a list from church this morning that shows ways I might live sustainably and better care for a divinely created earth by limiting my consumption in specific ways. As checklists define sustainability as separate, distinct actions that might sum to health for the earth or future generations, a sense of wholeness, which the concept of sustainability seems to attempt to invoke, seems lost. My walk through the grocery is more an experience of negotiated consumption than of mindfulness of the earth. Similarly, a definition that names sustainability as an action overlooks the need for a new way of knowing that informs our action. A definition that seeks a fulfillment of people's needs seems to overlook the earth's needs. And the failure to consider the earth's needs seems to have gotten us to the place we are in now, seeking to understand sustainability and live sustainably because our failure to do so is causing global climate problems.

Ironically, the concept of sustainability has become paramount because of humanity's current failure to carry out the action that its definition suggests. The Intergovernmental Panel on Climate Change (2007) argues that an increasing global population combined with increased use of emissions-producing technology has caused a level of resource depletion, emissions, and waste that has created a situation in which human behavior is pivotal for determining for the rate of climate change. For arguably the first point in the history of the earth, human behavior is a deciding factor in determining the future state of the planet (Nickerson, 2002). As scientists tout the need for human behavior, the paradigms guiding society's view of the nature of the relationship between the earth and humanity are shifting.

Thirty years ago in the United States, most people operated out of a paradigm in which humans held a level of control over the earth. A new paradigm, with incorporates a more "ecological worldview" in which people are seen as in relationship with the earth, is emerging as populations learn more about the effects of human actions on the environment (Dunlap, 2008, $p$. 9). Yet, as I highlighted with my own experience with trash, contemporary culture tugs us away from, out of, and on top of the earth as consumers. Even as an ecological paradigm emerges, the fact that it is emerging suggests that it is not natural or normal. Just as learning the names of trees, birds, and bugs seemed like learning a second language to me when I was a Girl Scout, taking on this new ecological paradigm seems like learning a second paradigm. Like a first language is always primary, the first paradigm seems to have a rooted position in our understanding, even as we might try to move from it. Even though I want to live sustainably, I still have a desire for characteristics of a lifestyle that feels innocuous. But, I begin to see as harmful when I live with earth in mind. In many ways, living with earth in mind is difficult because of my place is a historical trajectory of philosophy and language that have removed earth from consciousness. 


\section{Philosophical and Lingual Obstacles to Sustainability}

We continue to pour concrete, erect buildings, bridge waters, wash away bugs, throw our trash "away," and name the world around us. David Abram (1996) suggests that some consider "a generally exploitative relation to the rest of nature" as "part and parcel of being human" (p. 93). He counters this notion and instead claims that European civilization's neglect of the natural world and its needs has clearly been encouraged by a style of awareness that disparages sensorial reality, denigrating the visible and tangible order of things on behalf of some absolute source assumed to exist entirely beyond, or outside of, the bodily world (Abram, 1996).

Discussing the element of human domination over earth in Judeo-Christian views and the reason-based and anthropocentric Aristotelian logic, he highlights how people have learned throughout time and a modern epistemological trajectory (from Aristotle, to Descartes, to the Enlightenment) to interpret the world in such a way that the earth itself becomes something to be controlled or something to be transcended. Because the human ability to reason has become the primary source of knowledge, we have moved away from a more nuanced understanding of knowledge in which the earth might have contributions from which we could learn. The earth is not something to interpret, something that has a voice with which to speak, and something with which we can enter into a bodily relationship. As we do not consider the earth as relational, why would we consider that is has needs or what those needs might be? Yet the earth's "voice" has much to say about our need for sustainability. One might look only so far as the consequences of the BP oil spill, the thick clouds of pollution in Dallas on a humid day, or the melting ice caps to see that the earth is providing clues that are a result of our own anthropocentric reasoning. We have reasoned ourselves into the very needs (gasoline, industry, technology) that have perhaps increased human capacity for survival but have also caused the earth to respond in cautionary ways.

Abram (1996) continues, making the case that the rise of an alphabetic language in some ways began a human disengagement with the earth. Where once pictorial representations pointed to actual elements in the world (trees, water, plants), the Greek alphabet evolved as a phonetic script. In it,

(...) The written character no longer refers us to any sensible phenomenon out in the world, or even to the name of such phenomenon . . . but solely to a gesture to be made by the human mouth ... It was only ... with the transfer of the phonetic writing to Greece, . .. that the progressive abstraction of linguistic meaning from the enveloping life-world reached a type of completion. (p. 100-102)

In other words, language evolved from pictorial designs that pointed directly to the world it represented to phonetic symbol that pointed instead toward a sound a person would make. Modes of communicating shifted from pointing toward the earth to pointing back toward humanity. The earth and its once essential involvement in patterns of communicating can more easily fade from a cognitively moving populous.

In contemporary understanding of the earth, frequently we do not sense the earth has any sort of voice. Philosophers and scientists have spent much time separating humanity from the earth and animals, elevating the status of humanity over the environment. Humans, we claim, are set apart because of our ability to communicate and interpret the world around us. We can name, understand, relate, and think critically, unlike any other species or known element. Steeves 
(2006) considers our interpretation of language among animals saying,

The fact that we cannot describe with any certainty the thoughts of what we call animals, and that they cannot describe their thoughts to us, suggests to many that animals do not have thoughts ... we ought not confuse thought with descriptions of thought. (p. 1)

Abram implies that humanity perceives its only ability to engage in linguistic practices while denying the same ability to animals and the earth precisely because humanity has created its own language apart from the earth. Re-storing the earth, then, requires a turn to the thing - the earth and our relationship with it - itself as "the immediately intuited essential [element] of consciousness" (Moran, 2000, p. 108). We must consider this relationship with the earth as we seek to live in relation to an earth our very language has bypassed.

\section{Un-earthing Pathways to Knowing and Perceiving Earth in Mind}

In responding to an anthropocentric development of ancient and modern enlightenment philosophy, Abram (1996) seeks a way of understanding methods of communicating that he experiences when studying tribal "magic" and medicine in Bali. While noting cultural explanations for communities' understanding of magic, he also notes ways in which the shamans in the communities he visits respond to and witness the earth in ways unfamiliar to a traditional Western sensibility, such as his own. Abram (1996) states:

Magic, then, in its perhaps most primordial sense, is the experience of existing in a world made up of multiple intelligences, the intuition that every form one perceives from the swallow swooping overhead to the fly on a blade of grass, and indeed the blade of grass itself - is an experiencing form, an entity with its own predilections and sensations. (pp. 9-10)

He notices in Bali that the earth retains a voice that it has been denied in European traditions, and the earth is an experiencing rather than a static entity. Abram provides a guide for us as we try to live sustainably. He suggests we must move from our trained sources of logic and phonetic language to a way of living and knowing that recognizes the earth as a being that might enlighten our own reasoned knowing.

Moving Abram's' musings from a trip to Bali back into conversation with Western trajectories of thought, David Orr (2004), an environmental scientist, highlights how the power of our reasoned knowing can be troubling:

Most ancient civilizations knew what we have apparently forgotten: that knowledge is a fearful thing. To know the name of something was to hold power over it. Misused, that power would break the sacred order and wreak havoc. Ancient myths and legends are full of tales of people who believed that they were smarter than the gods and immune from divine punishment. But in whatever form, eating from the tree of knowledge meant banishment from one garden or another. In the modern world, this Janus-like quality of knowledge has been forgotten. Descartes, for example, reached the conclusion that 'the more I sought to inform myself, the more I realized how ignorant I was.' Instead of 
taking this as a proper conclusion of a good education, Descartes set about to find certain truths through a process of radical skepticism. (p. 17)

Orr continues to argue that a Cartesian search for truth from a cognitive, rational approach, limits our scope of knowledge and our ability to truly engage with the world. This cognitive, textual knowledge sets us apart from other species but also sets us up for ignoring forms of knowing that exist outside our textual boundaries, such as a relational knowing of the earth. Living sustainably requires that we break from anthropocentric reason, in which we can know and name the earth objectively, to a place in which we re-store the earth and instead of claiming to know it, seek to listen to what the earth might have to say.

Orr (2004) makes the case that objective knowing, such as that fostered by a rational and reason-driven society, has left its scars throughout our known history:

It is worth noting that [the climate crisis] is not the work of ignorant people. Rather, it is largely the results of work by people with BAs, BSs, LLBs, MBAs, and PhDs. Elie Wiesel once made the same point, noting that the designers and perpetrators of Auschwitz, Dachau, and Buchenwald - the Holocaust - were the heirs of Kant and Goethe, widely thought to be the best educated people on earth. But their education did not serve as an adequate barrier to barbarity. What was wrong with their education? (...) I believe the same could be said of our education. Toward the natural world it too emphasizes theories, not values; abstraction rather than consciousness; neat answers instead of questions; and technical efficiency over conscience. (pp. 7-8)

Orr asks that we consider the consequences of an education that excludes multiple forms of knowing. When rational thought produces the holocaust, what measures do we have in place to check rationality? When theoretical progress creates a global climate crisis, how can we reinsert the earth into a dialogue in which it has here to fore been ignored?

While certainly a society without a phonetic alphabet has ethical problems and while the anthropomorphizing of the earth as a dialogic partner might be far-fetched, Abram and Orr make compelling cases about the ways in which we have "turned off" our attention to the earth and the lessons its holds. The path of rational truth seeking has left us without the ability to question the consequences of our truths, for if something is true or factual, how can its consequence be wrong? If air conditioning provides us cool in the summer. If heat provides us warmth in the winter. If cars take us where we need to go. If airplanes can quickly unite us with loved ones. If mass production of chicken makes dinner easier, more affordable, and more protein-rich. If water is clean and abundant. If take-out containers make buying lunch convenient. Why wouldn't we air condition, heat, drive, fly, buy, use, and toss? When all we have to consider is the rational progress these elements afford, we do not even understand these actions as decisions that we make. Instead, they are simply signs of participation in a modern society - less decisions and more accepted patterns of being. Yet, if we consider the way in which the earth and the atmosphere are responding to such participation and, in turn, the ways many neighbors around the world are suffering because of the earth's response, no more does a rational participation in progress hold true.

We must attend to the earth, the connections of humanity with the earth, and the ways in which our lives might honor those connections. We must engage our everyday experiences as decisions with consequences that ripple out into the earth and into humanity in ways that beg us 
to listen, observe, and know. Given the need to step outside of our traditional modes of knowing, Orr (2004) suggests, "It is a matter of no small consequence that the only people who have lived sustainably on the planet for any length of time could not read, or like the Amish do not make a fetish of reading" (p. 8). Sustainable living requires that we move beyond the page and the word to live an experience of connection with the earth and others.

Given the obstacles to holding earth in mind, I question what is it like to live and think within a Cartesian world and yet work to move outside of it in order to re-store the earth? What is it like to inhabit a world whose language no longer references earth and attempt to again see the earth directly? What is it like to study within a rational educational system and honor multiple ways of knowing? What does living sustainably mean in a world where it seems all but impossible?

In light of the separation of objectivity and subjectivity and the ways it has distanced us from the world, phenomenology becomes a methodology that can return these once competing ways of knowing into conversation. Moran (2000) shares, "The whole point of phenomenology is that we cannot split off the subjective domain from the domain of the natural world as scientific naturalism has done" (p. 15). Phenomenology can allow us to engage domains of knowing in order to better understand human connection with the earth and the ways in which we live out those understandings. Phenomenology engages not only rational knowing but also perceptual knowing, providing inroads into examining what living sustainably means. Through it we can explore what it looks, feels, smells, tastes, and sounds like to live with the earth in mind and what sense we make of each of these different ways of perceiving. We can both use and remove ourselves from the cultures that enshroud us to see them for what they are, whether dismissive or inclusive of the earth.

\section{Turning to Lived Experiences of Earth in Mind}

Abram (1996) and Orr (2004) have shown the ways in which sustainable living, or the lack thereof, might be tied into knowledge production, language, and education. In light of these connections, I move to a setting of knowledge sharing and production - a university campus. I interviewed two college students to ask about their experiences of living sustainably. I met with each student for a formal interview twice and have seen these women at work for sustainability formally and informally across campus many times. Our e-mail exchanges and conversations have continued outside of the formal interview settings. Students at a large American MidAtlantic state school, Rita and Joann were both pursuing an interdisciplinary major that incorporates study of the environment. They served as peer educators for sustainability on campus, visiting freshmen orientation classes to teach about sustainability. They were also involved in various sustainable initiatives on campus. Joann served on the student government's sustainability committee, coordinating efforts for sustainable gardens on campus, and helped to create a new academic program in sustainability. Rita led and participated in a number of service-learning trips focused on sustainability, and she is the teaching assistant for introductory classes for her major. These women provided a view into what it means to live sustainably.

Reflecting on Rita and Joann's experiences, four areas emerged that help illuminate the experience of living sustainably. I describe the ways in which these women work to up-hold the earth, involve humanity, both study and embody sustainability, and choose beyond perception. 


\section{Up-holding the Earth}

I have demonstrated thus far that the earth has largely been removed from a contemporary consciousness, yet the concept of sustainability requires one to bring earth to mind. Given contemporary language and culture largely lead us to dismiss earth, what is unique about and what does it mean to live with earth in mind? Does a sustainable lifestyle entail a tangible interaction with earth? Joann and Rita help illuminate, what role earth plays in a sustainable life? Rita shared that she joined one particular club to hike, camp, volunteer to clean trails, and to "learn to love those activities more." These "direct connections" with nature help her to live with the earth in mind. She says an awareness of connections with the earth make one "less likely to make decisions that directly harm the forest or directly pollute water bodies when [one] can appreciate the beauty and ecosystem services of nature." Yet, she also says camping, hiking, or being outside in nature instills peace:

It's evoked more an idealism of simplicity . . . You're not going to bring your whole make up case, and you're not going to care about showering every day . . . You're not going to be so dependent on your CD player and on stuff and on technology. You're going to be more in connection to people that you're interacting with . . . I'm not bombarded by advertisements, people telling me to think a certain way . . . It's this type of serenity where I can get a lot of clear thinking out ... it's a recharge time and inner peace ... I think [being in nature also] provides extra motivation . . . it does engrain a philosophy of wanting to protect nature for the sake of nature but also for the sake of resources and how people can use them too.

Being outside takes Rita out of a technological and "stuff-filled routine" into a place where she can live simply. The world "simple" comes from the Old French, meaning, humble; and the world "humble" can be traced to the Latin root "humus", meaning "earth" (Online Etymology Dictionary, 2010). Thus, as Rita finds simplicity in nature, she returns to the earth itself. For Rita, being outside entails an element of retreat - escaping from a busy life into nature.

Joann discusses an experience growing up in a rural community where the earth was engrained in the community, rather than place of retreat. A co-op was her only grocery store. She went to farmer's markets each weekend. She hiked, gardened, and played outside as a child. Yet despite an awareness of the earth being more of a routine than it is for Rita, Joann still finds that "nature is a peaceful place." It is where she goes to be "restored." Just as she re-stores the earth by living with it in mind, the earth restores her by providing a sense of peace. The reciprocal relationships Joann and Rita describe are one set of roots in their sustainable living. Nature provides wholeness, peace, and beauty. In return, they seek to uphold nature so that it might continue to flourish.

The word "sustainability" itself conjures the notion of upholding that Joann and Rita enact. The root of "sustainability" is the verb to "sustain." Sustain, from the Latin "sustinēre," combines both the prefix, "sus" with the Latin verb "tenēre." "Sus" is a version of "sub," meaning under, up to, or towards. Tenēre is a verb meaning to hold. So to sustain something is to hold it up, or to uphold it.

This look into the meaning of sustainability gives a unique understanding of the way in which we might understand the term. We might both literally and figuratively uphold something. 
What does it mean to uphold? Upholding something requires first a recognition of something that can be upheld. Rita describes this recognition that itself comes from her being out in nature. She chooses to be outside so that she may remain in frequent awareness of the beauty of the earth. In recognizing it, we uphold it when we act to support it and honor its existence. We do not simply hold it, as we might hold a bag for a friend or the door for a stranger. But we hold it "up," giving it structure, support, and foundation. We might also hold it "up" as something to be valued. Thus our sustaining of something is our honoring and supporting of something.

What, then, exactly is being honored, upheld, and valued in the minds of Joann and Rita? "The earth" conjures different places for each - one, a wooded retreat and another a small-town home of gardeners, composters, and neighbors. Language becomes fluid for each as we discuss earth, the environment, animals, rocks, outside, and nature. We move in and around these words, each complex while used simply, yet in a conversation they refer to a similar construct: something outside ourselves that is not man-made (even if it is mediated by social constructions). Joann reflects on her conceptions of the earth:

I think about the deer and turkeys that would run through our yard. Or the apple orchard down the street. Or the blackberry patch ... [We were talking] about this in class - The difference between nature, wilderness and the environment. Nature with a lower case $n$ is more like the world as we experience it. Nature with a capital $N$ is a more ethereal, idealistic envisioning of the earth. I think for me, nature is a peaceful place.

Nature, then, may be perceived in different ways. Joann describes animals and plants that live outdoors that she associated with a former home. Yet she also reminds us of the "world as we experience it" versus the world as we "idealize" it. She highlights that our lived experience of earth may be very different from our imagination of earth. In a phenomenological sense, one might note that neither our lived experience nor our imagination of earth likely represents the real earth. Merleau-Ponty (1962) suggests, "Human gaze never posits more than one facet of the object" (p. 69), and thus sees an entity such as the earth only partially and then only characteristics that make it visible within a contrasting background. Consider Joann's recollection of picturesque experiences of earth - turkeys and apples. We are not called to see perhaps off-putting molds or slugs. Earth remains in her mind as a place of beauty as she appreciates nature and in it finds peace; beautiful, peaceful elements of the earth appear while other elements are not primary.

In fact, she contrasts others' understanding of earth as dirty and offensive. She described working with teenagers on invasive species removal. It was "hard work" with "serious tools" in the "hot summer." The teenagers complained, and she reflected, "If you grow up in a sterile, airconditioned society, it can be hard to be outside." Similarly, she worked with teenagers in a garden. When she "took some food from the garden and encouraged everyone to eat it, [she] always got the response: 'Gross that came from the dirt! I won't eat that!'”

Where one finds apple, another finds dirt. Where one finds peace, another finds unpleasant labor. The earth, then, which I claim is upheld in a life of sustainability, is not a stagnant entity. Each person prescribes one's lived experience onto their interpretation of the earth; from their experiences growing up, Rita finds a retreat in nature and Joann finds in it a reminder of home. One also prescribes socially constructed understandings of the earth onto the earth, understandings that earth is perhaps a place of simplicity, peace, beauty, or ugliness. What seems important, then, in a sustainable life is that first, one's gaze does consciously include the earth; it 
perceives the earth apart from a homogenous backdrop because "a really homogeneous area offering nothing to perception cannot be given to any perception" (Merleau-Ponty, p. 4). Second, the facet of earth one's gaze posits is one that is deemed worthy of upholding. For Joann and Rita, the gaze lands on a number of facets to be upheld - animals, rock, communities, peace, beauty, water - and these inspire the lives they lead. Much of their belief in the worth of the earth stems from direct connection to it in ways they found personally restorative. Their perception of earth and appreciation for it then fueled their work for it, such as Joann's laborious summer in the heat.

These women both describe that in their work to live sustainably; they uphold the earth and in return uphold themselves and others. Rita's "philosophy of wanting to protect nature" is both for the sake of the earth and the sake of others while Joann's consciousness of the earth inspires not only her re-storation of the earth but also her own re-storation. While they perceive of the earth, they also perceive of humanity in relationship with earth.

\section{In-volving Humanity}

A way of knowing that requires one to think beyond oneself shows how living sustainably requires living not just with the earth in mind but also with people in mind. Sustainable living entails a community-oriented mindset. Rita describes the "classic" triple bottom line of sustainability as the "intersection between society, economy, and the environment." Attention to the environment or the earth, therefore, is only one element of a lifestyle that involves holistic living in a society. The earth is a home to people. As far as we can conceive the universe, is the only planet with life as we define it. Earth is set apart from the rest of the planets in the universe because it sustains people and life. As Arendt suggests, we are not simply "in the world" but "of the world" (Moran, 2000, p. 289). The term sustainability deals with the concept of people sustaining the earth; yet, might the earth and humanity sustain each other? And if so, in sustaining the earth might we also be looking to sustain people themselves as we sustain the very thing that sustains humanity?

Rita reflects on why she likes visiting farmers' markets: "I get a lot of joy out of making those people connections with my food instead of it being an abstract object that I pick up off the shelf based on the lowest price." She enjoys engaging in a community and knowing the farms and farmers that help grow food she eats. She also describes an alternative spring break trip to help with an urban agriculture program that donates food to local hunger organizations in a large city on the east coast:

People are environmentalists and care about sustainability because they care about people. I think that's why I'm so into food, because I see how nutritious food connects to people. And when the participants go on these trips ... they are seeing how real life people and problems can be solved using sustainable solutions

Rita connects earth and humanity when she considers food, agriculture, and people. Joann thinks about the human-earth connections as she compares her experiences in two different communities that enact these connections in different ways. During an international trip studying permaculture, strangers find connection with each other. On campus, however, people remain on separate paths. Joann described the differences: 
They weren't intentional communities, so there were still parts of land that were very separate. But they still had community areas and common areas. There were two families that we met there (...) and they have their own houses that they have built from sustainable building materials, so bamboo, like recycled and salvaged materials. And they have rain water catching systems and wells, so they don't have municipal water. But they are really, really water conscious (...) And they run on solar energy, so the electricity wasn't on all the time, so they just turn it in the evenings, when it was necessary, like to cook in the kitchen and stuff. Just things like that. It's such a natural way of being. We woke up really early, around 6 , when the sun came up and then we went to bed around $8: 30$ or 9 because it was dark and there wasn't much else to do (...) and there weren't many people in our group who felt uncomfortable. But for those that did, we talked about it a lot. That sense of comfort, and we came to the consensus that our degree of comfort and discomfort comes from a relative sense of where we're from (...)

When I came back to campus, I was so jolted and confused because you're walking on campus and everyone is walking with their head down with their headphones in and not making eye contact with anybody and it's like an ant hill, like you're like work, work, work, going on my separate path like don't bump into me, but yeah I don't know I feel like, having that sense of community and connectedness to each other contributes to good spirits.

Joann describes the plugged-in culture of campus that differed from the country she visited, where plugging into the electricity was literally possible only a few hours of the day. One can also imagine the differences in the perhaps earth-trodden paths around the farms on her trip and the concrete sidewalks on campus. Communities and people take on different meanings when interacting with others is one of few potential past times. On her trip, people worked on the farms together and in their pastime, spent time together reflecting and talking. On campus, people remained individuals, refraining from eye contact or even from brushing next to someone on the sidewalk. One cannot ignore the ways both earth and humanity remain in mind for the community on the trip and the ways in which both earth and humanity move to the background in a world where ears are plugged and eyes are turned to the concrete. With earth in mind on her trip - and little else - Joann notices the way in which community moves to the forefront. Interacting with people becomes a past time and caring for earth becomes an extension of caring for others as the health of the land determines the health of the community. On campus, though, the individual moves through space and community, able to choose when to pay attention to both earth and others, in times of convenience, boredom, or interest. Joann noticed how returning to direct care for the earth shifted her perspective on community.

Rita shares a similar sentiment. When I asked her about the earth and its relationship to her lifestyle of sustainability, she spoke about the importance of nature. But she re-emphasized, "I'm in it for the people." She shared:

I think that sustainability comes with the ability to think outside of yourself and think outside of your own needs. So just the ability to think collectively, think about the people around you and maybe even people that haven't been born yet, like maybe your kids and grandkids, and things like that. So just not thinking about what would be easiest or most convenient for you but looking at humanity as like a collective being. 
Living sustainably is not just living out values for oneself, then, but living values that see the "collective" of humanity. Rita lives the value of seeing the collective of humanity in the ways she spends her time. Educating, serving, studying, eating responsibly, and purchasing responsibly all tie into her consideration of the presence of people both locally and globally. Tony Cortese (2011), President and Co-founder of Second Nature, recently shared that sustainability is not a question of "saving the environment." The environment has survived a number of crises, climate changes, and species extinctions. The question is, "How do we meet the needs of all the people on the planet?" People, then, are at the heart of sustainable living. Earth is an elemental consideration in the lives of the women with whom I spoke, but the earth involves humanity.

To suggest that people are at the heart of sustainable living seems perhaps anthropocentric - potentially hypocritical in light of earlier attempts to suggest that humanity has denied the earth dignity in the practice of promoting itself. Steeves (2006) reflects on this very anthropocentrism when he suggests, "We have been privileging the animals that speak" (p. 6); and, he highlights the usual tone of liberal individualism that accompanies such anthropocentrism when he notes that "our ways of cashing out ethics have tended to focus historically on the individual" (p. 135). At the same time, what is sustainability without humanity? The concept itself is created by (flawed) human logic, needed because of eras of human error, and concerned with survival of human civilization. In my own language, I discuss the return of earth to mind, to consciousness the term considers not a return of the earth to itself but to human thinking or imagining. Sustainability, therefore, involves humanity.

Turning again to etymological foundations, the Latin "involvere" means to "envelop, surround, overwhelm" and literally "roll into." In other words, sustainability is rolled into humanity - without the later the former would not exist. The image of our exponentially populating species enveloping, surrounding, and at times overwhelming the earth seems apropos. Living a sustainable lifestyle entails moving nimbly, thoughtfully, and lightly in an earth that is crowded with humanity and earth-dismissing ideologies, especially when one cares both for the humanity that is dismissing and the earth (including rock, soil, animal, atmosphere) that is dismissed. As the concept of sustainability itself involves, envelopes, surrounds, and overwhelms humanity, it entails a new way of living in which humanity sees once overlooked relationships among people and earth.

While it may be its flaw as well as its appeal, the tandem concerns for earth and humanity seem woven into a sustainable life. As much as the term sustainability is about recognizing, listening to, and tending the earth, it is about bringing people into relationship with the earth. And as Joann and Rita describe concern for others and experience living in community, their experiences of sustainability offer a response to liberal individualism by moving ethics to the realm of community and relationship, between and among humanity and earth. To live sustainably means to adopt the mindset that we must be mindful of each person's, each community's needs as well as those of the earth and the inhabitants of the earth. How then do we learn such mindfulness? Can it be studied? 


\section{Studying or embodying sustainability}

While both Rita and Joann study sustainability, this studying does not necessarily translate into a sustainable life. Rita brought up the notion of a difference between studying sustainability and living sustainably. What might it mean to live out the values of sustainability rather than to study sustainability? Rita talks about the nuanced differences between the two as she lives and studies sustainability:

One of my roommates is [in a major related to the environment]... she studies [sustainability] but I don't know about living it . . . It's like you can learn about environmental issues but not connect it as well to daily life. I think that's the difference between being a ... major and being sustainable ... If you're living the lifestyle of sustainability, you're incorporating what you learn in environmental science classes, you're incorporating what you know about the food system or about the cleanliness of water or about the polluted air or about vehicle emissions . . . into your life. I've had environmental science teachers who eat fast food all the time. I'm like, "what are you doing?" It's like they have that area of expertise but it doesn't get holistically incorporated into their lives. And I look at my roommate or I look at other friends within my major, and it's like they study what they study, they want to do science research, they want to help mitigate air pollution, and they get it, but then other things just don't click. It's not as much of a lifestyle. And it's something they learn about and they write papers about and they focus their life on . . . You don't really learn principles of sustainable living in the classroom, it's hard to do that.

Studying sustainability does not necessarily mean that someone will then live sustainably. Rita highlights that "learning information" does not necessarily translate into "synthesizing" that information in a way that results in a sustainable lifestyle. What is the difference between living and studying, as she describes it? The idea of living might bring forth notions of daily interactions of living - eating, sleeping, and moving from place to place. The idea of studying might evoke visions of reading, sitting in the library, engaging in a class, or testing a hypothesis. Certainly, studying can be part of one's living, especially if one is a student or professor. But, can living be a part of studying? Can we study to live in a certain way?

Joann describes choosing to study the environment after she grew up tending the earth and its creatures. Yet, her choice of major surprises her parents. She reflects:

Where I grew up for a couple years, my mom had a vegetable garden by the side of the house, we had a compost pile, we had a blackberry patch. My mom always used to tell me not to pick at the bottom because that was for the animals that would come by. So always pick at people height. There was a lot of wildlife running in and out of there, and I remember one time a bird flew into the window and my Dad nursed it back to health, and I remember watching and being really fascinated by it ... It seems [my awareness of the environment] was kind of always there, as the context as how I grew up. Which is funny because when I choose environmental science, my parents were blown out of the water. They didn't really understand why I was choosing to study this.

Joann's parents modeled a way of living with the earth in mind, yet they were surprised 
when she chose to focus on the environment in school. They did not assume a way of life would translate into a subject of study.

Knowledge about a way of living is "hard" to learn. Rita and Joann, in attempting to live sustainably, encounter dissonance between cognitive knowledge and lived knowledge. On one hand, studying about sustainability does not translate into one's embodiment of sustainability. On the other, studying the environment might be seen as a topic for learning through experience rather than through academic exploration.

These women encounter problems with what has become the legacy of Descartes, the primacy on rational thinking as knowledge. Evernden (1993) describes how, in retreating to our thoughts and treating our cognitive abilities as a sole source of knowledge, we remove ourselves both from our "environment" and our 'body" (p. 45). We deny knowledge that lies within our bodily experience with the environment. Rita experiences the "barrier between man and nature" (p. 53) that Cartesian ways of thinking establish. Thinking about, knowing, and studying the environment cognitively does not translate into living, carrying out, and experiencing a relationship with the earth. In the same way, Joann encounters at least initial resistance to the idea that an experience-based relationship with the environment should or could be studied.

Attempting to live sustainably brings to the forefront dissonance between one's cognitive knowledge and one's lived knowledge. In so doing, it highlights ways in which holding earth "in mind" is perhaps a necessary step in a rational world, but not the final step in carrying out a life of sustainability. The women admit this disconnect themselves. Rita regrets, "I am not the perfect model.... there is so much more I could be doing." She continues:

I feel like [my] day to day operations change based on new things I learn or based on practical solutions I see to problems. Maybe living sustainably wasn't practical but I found a way to get around it, I don't know if that makes sense.

While she second-guesses her thinking, she attempts to describe how she works to embody sustainability in her life as she continually learns through her experience in the world. She works to enact both studied and embodied knowledge; at times, rationality deems sustainable living impractical, but she moves forward despite the uncertainty. Earth in mind helps turn her toward sustainability in embodied living, yet her experience in the world helps her learn each day what sustainable living entails.

Joann and Rita, while they each study sustainability, learn to embody sustainability through experiences outside of the classroom. Above, I shared some ways in which Joann describes learning to live sustainably at home in a rural community in New England. Learning to share the fruits of plants with animals was a backdrop of the ways she interacted with the world. Her relationship with the earth entailed an awareness of sharing the earth with animals. She also talks about her mother's insistence that clothes be line-dried in the summer months. She remembers being scolded if she used the dryer during June, July and August, given the unnecessary pollution when clothes could dry naturally outdoors. These experiences seem crucial to her own learning, yet she says she has difficulty "pinpointing" how she learned to live sustainably. What Rita describes as "hard to learn," Joann describes has hard to "pin point." What is so hard to describe for these women? Both gave textbook definitions of sustainability and speak beautifully about topics related to sustainability, yet describing what living sustainably is or how they learned to live in such a way feels difficult to them both.

Part of the difficulty is likely the result of a rational intellectual culture - the language of 
thinking and rational knowing does not easily align with the language of being and knowing in an embodied way. Rational knowing seeks that we "fail to disprove" hypotheses, increase our "probability" of being "accurate," and bolster "our confidence" (Evernden, 1993, p. 54). Yet, embodied knowing entails highly perceptual knowing. Merleau-Ponty attempts to describe perceptive knowing in his consideration of color. The color green might have many different values depending on its use, pigmentation mixture, or exposure to light. Yet, all of these values might be described as green, and we use color to describe or name an object. Merleau-Ponty (1962) suggests, however, colors are not "sensations but sense-data" (p. 4) and the felt quality of an object is not "an element of consciousness, but a property of an object." What we claim to know about the world and our being in it is as much, if not more, related to our perception of the world than to the actual world itself. Merleau-Ponty continues, "We are involved in the world and we do not succeed in extricating ourselves from it in order to achieve consciousness of the world" (p. 5). These women can name ways they rationally know they attempt to live sustainably and events they associate with their awareness of earth. Yet, they cannot easily pinpoint an essence of their way of living because they can only name qualities of such a life. Just as it might be difficult to describe the specific value of green in a plant, so might it be difficult to describe one's embodied attempt to live sustainably. We can talk around it, provide stories, and give context. Those ways of touching the edges of the value somehow give the value objective form and quality but not exact definition.

The form and quality of the values Joann and Rita relate to sustainability are rooted in a lived experience, as much as they are in an information-full education that Rita describes as inadequate for living sustainably. Rather than reading about the values or talking about them abstractly, they engage the values in body and in experience. Merleau-Ponty suggests, "We grasp [the world] according to the mode in which we inhabit it. Humans can only understand the world as it is revealed and uncovered ... with our specific forms of being-in-the-world" (Moran, 2000, p. 43). He speaks to the kind of revealing, experiences that Joann and Rita describe as it informs their own lifestyles.

\section{Choosing Beyond Perception}

While they may only be able to point to qualities of their sustainable lifestyles, one quality that characterizes their experience entails the daily decisions that open to them when they live with earth in mind. In my own turning to sustainability, I described internal negotiations when eating or working. Joann and Rita similarly describe that living sustainably entails making choices about daily actions some pursue with little contemplation. Joann describes the choices she makes each day, some which have become habit:

I hold myself to the things I commit myself to. Each morning, the first thing that I do when I wake up is to fill my water bottle . . I use my water bottle so I don't have to buy water. I have a recycling bin in my own room. And I try to put everything in my backpack each morning. I buy groceries as often as possible, and when I come to campus I find it wasteful to buy food when I already have food at home. But for a while, I was always buying food on campus. So I try to pack food for the day. I also use my laptop. I am in a lot of classes with PDFs on Blackboard, and I don't like to waste all that paper. So I read them on my laptop and bring it with me.

In each of these activities, Joann makes a choice that entails a number of considerations 
about the environment, other people, and herself. Even small things like drinking water or reading for class become wrapped in choices - do I buy a bottle or take one from home? Do I print or read on my computer? While for some, these activities do not evoke any sense of the need to make a choice. Staying hydrated and doing homework need to be done; those activities are not choices. So, the manner in which they are done is not necessarily up for consideration. The fact that they Joann and Rita believe certain activities require choices is telling. Rita shares:

I learned a lot about the environment right off the bat after coming to campus. And at [a natural grocery store], where I worked, I was taught a lot about sustainability and taught about things that you wouldn't think about in your daily life . . . How would you know about deforestation in Brazil and how that relates to carbon emissions in the atmosphere because carbon can't be captured by those trees? Or [about] people using that for farm land, and then it's being created into ethanol when we could be growing food .... if someone hadn't told you? (...) Because of [my] knowledge I feel the way my life is has to be different. It's like I think it is all about choices but it's easier to make those choices and see the rational for those choices and to be motivated to inconvenience yourself sometimes because you see how it relates to the bigger issues and the larger picture ... I don't see [sustainable choices] as hard choices because I see how much they can difference or if other people were to make the same type of choices, and the movement kind of spread, I could see how much it could make a difference.

Living sustainably requires that we make choices in places where choices might not appear on the surface. Seeing beyond the surface requires learning about the picture and depth of the situation beneath the surface - making the invisible visible. These invisibilities in the sustainable community are even called "externalities" because they are "extra" costs that do not appear on the surface. In living sustainably, Rita and Joann choose to see that actions, even small daily actions like drinking water, are activities that require decisions because these actions impact global communities and the environment. They have been taught about environmental degradation but then they decide to choose purposefully the manner in which they act based on that information. They work to think broadly rather than narrowly - to open up the possibilities and consequences of all that lies hidden behind each decision. Making choices produces not just a simple decision, but a series of ripple effects, moving out beyond the immediate decision.

Purchasing is just one such action whose effects ripple beyond the immediate decision to buy. Rita believes, "It's not just a few people who chose to buy fair trade who are going to change the world. It's the everyday consumer that knows what they are actually buying." People naturally purchase and consume. We consume energy, food, and building materials. Survival itself requires that people consume some of the earth's resources.

Rita calls attention to the fact that sustainable consumers must know what they consume. Do people then sometimes not know what they consume? Can it be that difficult to know what we eat, wear, and generally use? Rita describes that in living sustainably, consumption and purchasing require her to think beyond "taste or price." She thinks about who made what she purchases, how the makers were treated, what went into making the item, where her money goes, and what the waste might be. She says,

I mean, it's cliché, but I think about [my purchasing power] as a vote. Like when I buy that goat cheese from Pennsylvania, I'm voting for that farmer to do well. I'm supporting 
him and supporting his mission and supporting his cause, and also getting delicious cheese in return. But that does at least run through my mind. And when I choose to buy something at, like a shirt at [second hand store], rather than buying something from Abercrombie and Fitch, I'm saying that I don't think this shirt should be in a landfill, I think that it is still worth wearing, it doesn't have any holes in it, it is totally fine. Why am I voting for the Abercrombie and Fitch shirt, which most of the money for it was spent on marketing, most of the money is going towards corporate executives? Not a lot the money is going to the workers for it, not a lot of the money is going to the sales people -- they're paid minimum wage. I think about that when I buy things.

Purchasing and buying become different decisions when living sustainably. To know if a product is sustainable, one must ask a number of questions that are not usually readily apparent when at a store. The price of purchasing becomes not just the cost of the item, but the price that item cost to laborers and the earth. Purchasing becomes an activity that connects consumer with laborer with corporation with earth. It involves holding in mind that which is not perceptually apparent.

Rita and Joann both talk about how making choices is part of their sustainable lifestyle. They each know that they do not live perfectly sustainably, if such a concept could exist, and they admit they at times choose in ways that are not sustainable. And, in fact, perhaps that is part of living sustainably. Rita and Joann might suggest that one tries to live sustainably given the knowledge one has. Yet one's knowledge is always limited - by the limited awareness of all qualities of an object as well as by the single perceptive point one body holds. Yet, Joann and Rita gather their time in nature, their appreciation for humanity and its relationship with earth, and their knowledge about sustainability, and seek to make choices that best aligns with each. Recognizing that choices exist and will always exist; they open themselves to continual learning about earth, humanity, sustainability, and how to embody sustainability such that they can make decisions in-tune with their knowledge and perception.

\section{Living to Re-store}

Rita shares that once she learned so much about sustainability and saw its impact on the world, she could not not live sustainably. But, as she also tells us, some people can learn the same thing she learns and not live sustainably. So what is at the heart of living sustainably? What creates a sustainable life? Not just knowledge of the science of climate change or the information one might learn in a classroom. Rita and Joann tell us that living sustainably requires attention to values, which while perhaps hard to describe, ground a way of living that invokes connectedness. This connectedness involves a re-storing of the earth to one's mind and an experience of witnessing how the earth and humanity are interwoven in relationship. The relationship entails living with earth in mind, stepping away from domination of the earth and moving towards a life lived in constant awareness of and appreciation for the earth. Daily actions entail considering the consequences of those actions, and engaging with the world requires attentiveness to time, place, space, and the presence of people.

At the forefront of living sustainably are the interwoven concepts of knowing, feeling, and doing, seeming at once separate and simultaneous. Gaining knowledge through studying does not equate to embodying sustainability in a lived experience, but the two come together in Joann and 
Rita's lives. The feelings of peace from nature come, not from a scientific knowing of sustainability, yet inform a scientific knowing of the effects of climate change in ways that move one from a studier of sustainability to a liver of sustainability. The knowable definition of sustainability is simple to recite but the values learned through experiencing sustainably are difficult to describe without showing how the values are lived. Yet, learned definitions and experienced values both weave in and out of these women's descriptions of their lives. Knowing informs living and living informs knowing in a symbiotic relationship.

Much like the term "sustainability" itself, invoking a connectedness of people, the earth, and the economy, living sustainably requires a connectedness of knowing (e.g., both of and about earth), doing (e.g., responding to the reality that earth is in mind), and feeling (e.g., perceiving earth, humanity, and one's self). Living sustainably involves a holistic engagement of a person, with mind, spirit, and body engaging for one to know information about sustainability, feel the connections invoked by sustainability, and live the actions required by sustainability all the while accepting that a perfect of life sustainability is not possible. Living with earth in mind moves us closer to sustainability though our perception and knowing are limited. While Abram (1996) and Orr (2004) show how language and modern philosophy have moved us out of connection with the earth, Rita and Joann show us a lifestyle whose roots are planted in the hope of re-storing the connections of the earth and humanity to mind in the midst of an earth-dismissing culture. This lifestyle is played out in tangible, lived actions - through packing food, using water bottles, or gardening. Yet, it is also accomplished in intangible, felt actions - thinking about complex consequences of immediate actions, recognizing the invisible, conceptualizing the collective, and allowing space for relationships to develop with earth and others. These objective and the subjective actions must happen at once and in communion in a sustainable life.

The coming together of knowing and doing, objective and subjective, present and future, makes living sustainability an endeavor rooted in the principles of phenomenology. A sustainable lifestyle engages one in a kind of knowing that values empiricism but also moves beyond it. It calls one out of one's head and into both a lived and thoughtful relationship with the earth and humanity. It joins together bodily experience with one's own interpretation of that experience. With these connections, living sustainably moves towards a re-storation of each person with the earth and humanity as a whole.

\section{References}

Abram, D. (1996). The spell of the sensuous. New York, NY: Vintage Books.

Berry, W. (2002a). A native hill. In N. Wirzba (Ed.), The art of the commonplace: The agrarian essays of Wendell Berry (pp. 3-31). Berkeley, CA: Counterpoint.

Berry, W. (2002b). Think little. In N. Wirzba (Ed.), The art of the commonplace: The agrarian essays of Wendell Berry (pp. 81-90). Berkeley, CA: Counterpoint.

Berry, W. (2004). The long-legged house. Berkley, California: Shoemaker \& Hoard.

Cortese, T. (2011, April). Campus/community partnerships: The key to a healthy, just \& sustainable society. Keynote address at the Smart and Sustainable Campuses Conference, College Park, Maryland. 
Dunlap, R. E. (2008). The new environmental paradigm scale: From marginality to worldwide use. The Journal of Environmental Education, 40(1), 3-20.

Evernden, N. (1993). The natural alien: Humankind and the environment (2nd ed.). Toronto: University of Toronto Press

Intergovernmental Panel on Climate Change. (2007). Contribution of Working Groups I, II, and III to the Fourth Assessment Report of the Intergovernmental Panel on Climate Change. Retrieved from http://www.ipcc.ch/publications_and_data/ar4/syr/en/contents.html

Merleau-Ponty, M. (1962). Phenomenology of perception. (C. Smith, Trans.). New York, NY: The Humanities Press.

Moran, D. (2000). Introduction to phenomenology. New York, NY: Routledge.

Nickerson, R. S. (2002). Psychology and environmental change. Mahwah, NJ: L. Erlbaum Associates.

Online Etymology Dictionary. (2010). Retrieved from http://www.etymonline.com/

Orr, D. (2004). Earth in mind. Washington, DC: First Island Press.

Steeves, H. P. (2006). The things themselves. Albany, NY: State University of New York Press.

World Commission on Environment and Development [Brundtland Commission]. (1987). Our common world. Oxford, Great Britain: Oxford University Press. Retrieved http://www.un-documents.net/ocf-ov.htm 